\title{
Distribution of the spider community in the olive grove agroecosystem (Portugal): potential bioindicators
}

\author{
Jacinto Benhadi-Marín ${ }^{* \dagger} \mathbb{B}$, José A. Pereira*, José P. Sousa ${ }^{\dagger}$ and Sónia A.P. Santos ${ }^{\sharp \$}$ \\ * Centro de Investigação de Montanha (CIMO), Escola Superior Agrária, Instituto Politécnico de Bragança, Campus de Santa Apolónia, 5300-253, \\ Bragança, Portugal, ${ }^{\dagger}$ Centre for Functional Ecology, Department of Life Sciences, University of Coimbra, Calçada Martim de Freitas, 3000-456, \\ Coimbra, Portugal, ${ }^{\ddagger}$ CIQuiBio, Barreiro School of Technology, Polytechnic Institute of Setúbal, Rua Américo da Silva Marinho, 2839-001, Lavradio, \\ Portugal and ${ }^{\S}$ LEAF, Instituto Superior de Agronomia, Tapada da Ajuda, 1349-017, Lisbon, Portugal
}

\begin{abstract}
Spiders are successful natural enemies in different crops. Research on the role of spiders as natural enemies within agroecosystems needs to address the distribution of their communities across different spatial scales, as well as the dominant species.

2 We studied the spatial distribution of the community of spiders of the olive agroecosystem in Northeastern Portugal and investigated potential species that could be used as bioindicators of agricultural management in the olive grove.

3 We found nine functional groups (ambushers, foliage runner hunters, ground hunters, orb-web builders, sheet web builders, sensing web-builders, space web builders, stalkers and wandering sheet/tangle weavers) encompassing a community that changed significantly across the horizontal and vertical gradient.

4 We propose Thanatus vulgaris Simon, 1870 as potential bioindicator for the ground of the olive grove central area and Ozyptila pauxilla (Simon, 1870) for the ground of the olive grove peripheral area.

5 Adjacent shrubland areas could play an important role in biological control of pests, allowing the exchange of species and individuals with the olive crop. The role of agrobiont species as indicators of agricultural managements deserves further investigation towards the enhancement of the effectiveness of spiders within low-impact crop management in arable landscapes.
\end{abstract}

Keywords Guilds, indicators, margin, predators, shrubland.

\section{Introduction}

The suppression of pests by their natural enemies is a subject of interest for agricultural managers within sustainable farming practices. Agricultural landscapes are usually unstable environments for natural enemies as a result of moderate to high levels of disturbance caused by the application of cyclic and frequent agricultural practices (Landis et al., 2000). However, several factors can drive the spatial distribution of natural enemies enhancing their presence within crops. For example, the occurrence of ecological corridors between crops, the presence of different patches in the surroundings of the crop, and the availability of within-crop microhabitats can promote the abundance and action of natural enemies in the crop as a result of spillover (i.e. movement between crop and noncrop patches), the existence of shelter and supplementary food (Nicholls et al., 2001; Blitzer et al., 2012; Benhadi-Marín et al., 2018; Michalko et al., 2019).

Correspondence: Jacinto Benhadi-Marín. Tel.: 00351915720198; e-mail: jbenma@hotmail.com
Furthermore, the pest suppression exerted by natural enemies can be maximized by the existence of overlapping habitat niches (e.g. different vertical layers such as soil, trunk and canopy) that may allow their coexistence by reducing the intraguild competition (Dainese et al., 2017). Hence, crop management towards maintaining and promoting supplemental resources can improve the effectiveness of natural enemies against pests (Landis et al., 2000).

Spiders encompass a group of generalist predators that feed mostly on insects, they are well represented within the agroecosystems (Marc et al., 1999), and they have been reported as successful natural enemies in different crops such as apple (Wyss et al., 1995; Isaia et al., 2008), pear (Pekár et al., 2015), cotton (Ghavami, 2008), wheat (Oelbermann \& Scheu, 2009) and Brassica L., 1753 (e.g. broccoli and cauliflower) (Hooks et al., 2003).

Research on the role of spiders as natural enemies within agroecosystems needs to address not only the distribution of their communities across different spatial scales (e.g. vertical and horizontal patterns), but also the structure of the community 
by knowing which species are dominant within the agricultural landscape. Samu and Szinetár (2002) defined agrobionts as those species that reach high dominance in crops. These species can be indicators of arable habitats and could be used to monitor the quality and sustainability of the agroecosystem.

The olive tree cultivation (Olea europaea L. 1753) is an agricultural activity with high economic, social and cultural importance along the Mediterranean Basin where 95\% of the global production of olive oil is located (FAOSTAT, 2018). The olive fruit fly Bactrocera oleae (Rossi, 1790) (Diptera: Tephritidae) is the key pest of the tree and their larvae develop in the fruits, whereas pupae overwinter in the soil and adult flies are long-living and mobile (Civantos, 1999). Prays oleae (Bernard, 1788) (Lepidoptera: Praydidae) is another olive tree pest that completes its life cycle in the canopy (Civantos, 1999). Both of these species can be consumed by spiders both in the canopy as well as at the ground level (Morris et al., 1999).

Within the olive grove agroecosystem, several studies have been carried out encompassing different aspects of the biology, diversity and taxonomy of spiders, as well as an investigation of the influence of agricultural management and landscape on the community of spiders. In this context, Cárdenas and Barrientos (2011) provided a list of 142 spider species within the olive grove in Andalusian (southern Spain) groves; Cárdenas et al. (2015) found that organic farming favoured the abundance and diversity of canopy spiders compared with the integrated pest management and conventional systems. Picchi et al. (2016) found a negative correlation between the abundance of the olive fruit fly and cursorial and sheet web spiders, as well as a significant effect of the adjacent semi-natural habitat type on the spider family composition in Italy. Also, Cárdenas (2008) developed preliminary studies concerning the use of spiders as potential bioindicators of agricultural management in the olive grove agroecosystem.

Thus, there is an increasing interest on the role of spiders as natural enemies of olive pests; however, studies regarding the composition of the community of spiders within the olive grove and its surrounding landscape and their potential as bioindicators of agricultural practices are still scarce. The present study aimed to (i) characterize the spatial distribution of the community of spiders and (ii) identify agrobiont species that can be further used as bioindicators of agricultural management in the olive grove. Our working hypothesis was that the community of spiders is unequally distributed across the vertical strata (i.e. ground, trunk and canopy) and the horizontal spatial architecture (i.e. olive grove central area, peripheral area and adjacent shrubland area) of the grove considering species and functional groups. Also, we aimed to discuss the implications of the distribution of species for biological control, focusing on the biology and bioindication potential of the species found along the olive grove agroecosystem.

\section{Materials and methods}

Study area

The field work was conducted in May 2014, in five areas near Mirandela municipality (Trás-os-Montes, northeastern Portugal). Each area was composed of an olive grove and an adjacent semi-natural field. This field represents an important land cover type in the study region and corresponds to a typical Mediterranean habitat named 'matos' (shrublands) characterized by the herbaceous stratum dominated by plants belonging to Asterceae, Poaceae and Fabaceae families; the shrub stratum dominated by plant species such as Cistus ladanifer L., Cytisus sp., Lavandula sp., Rosmarinus officinalis L., Rubus ulmifolius Schott and Crataegus monogyna Jacq; and the tree stratum dominated by Quercus rotundifolia Lam., Quercus pyrenaica Willd. and Arbutus unedo L. The study sites are located in the Mediterranean climatic zone, Csa-type according to the Köppen-Geiger classification (Peel et al., 2007), which is characterized by hot and dry summers and mild and moist winters. The sampling area is located within a region with a mean annual rainfall of $776 \mathrm{~mm}$ and a mean annual temperature of $13.8^{\circ} \mathrm{C}$ (Fick \& Hijmans, 2017)

The five study sites form a polygon of $30 \mathrm{~km}^{2}$ with a maximum and minimum separation between groves of $9.71 \mathrm{~km}$ and $0.39 \mathrm{~km}$, respectively. The olive groves were rain fed: two of them were conducted under the Integrated Production system (Cedães 1 and Cedães 2) and three of them were conducted under the organic farming system (Guribanes, Romeu, and Valbom-dos-Figos). More details regarding the study sites are provided in the Supporting information (Table S1).

\section{Sampling of Araneae}

The horizontal distribution of the community of ground spiders was studied by sampling three areas: two areas were located in the olive groves (a central area and a peripheral area close to the hedgerow with the shrubland area) and a third area was located in the shrubland. The central and peripheral areas within the grove were located $150 \mathrm{~m}$ apart, whereas the peripheral and the shrubland areas were spaced $100 \mathrm{~m}$ apart. The ground spiders were sampled using four pitfall traps placed in each sampling area. Each trap consisted of a plastic cup (top diameter $115 \mathrm{~mm}$, height $130 \mathrm{~mm}$ ) dug into the ground and filled with $250 \mathrm{~mL}$ of ethylene glycol (anti-freeze liquid) as a preservative. A lid supported by iron wires was placed over each trap to exclude rain, debris and small vertebrates. Pitfall traps were placed in the south side of the canopy at $50 \mathrm{~cm}$ from the trunk (olive tree in the grove or shrub or tree in the shrubland) and were spaced 45-50 $\mathrm{m}$ apart. Traps were active for 14 days and were not refilled during the sampling period (i.e. each trap was used once). The vertical distribution of the community of spiders was studied by collecting specimens from the soil, trunk, and canopy in the same central and peripheral areas in the olive groves. The canopy spiders were sampled by shaking two branches per tree (duration of $5 \mathrm{~s}$ ), with one branch facing the south and another facing the north. Four trees were sampled using a funnel-shaped cloth (upper opening $0.42 \mathrm{~m}^{2}$, height $0.65 \mathrm{~m}$ ) that ends at its base in an opening over which a plastic bag can be placed to receive the sample. All of the selected branches were between 1.5 and $2 \mathrm{~m}$ in height. Spiders collected in the bag were preserved in situ with $70 \%$ ethanol to avoid predation. The spiders moving on the trunk were sampled using sticky traps (acting during 14 days). Each sticky trap was placed around the trunk (of the same trees sampled above) to capture the individuals inhabiting or using the trunk to disperse. Each sticky trap consisted of a 
strip of wrapping plastic transparent food film (30 cm in height) surrounding the trunk at $1 \mathrm{~m}$ in height and covered with glue.

All of the captured spiders were transported into the laboratory, sorted, preserved in $70 \%$ ethanol, identified to the species level (when possible) using a binocular stereomicroscope, and grouped in functional groups in accordance with Nentwig et al. (2018), Cardoso et al. (2011) and Uetz et al. (1999). Because all of the spiders captured on the trunk were immature, the richness of families instead of species was used in further analyses.

\section{Statistical analysis}

All statistical analyses and modelling were performed in $\mathrm{R}(\mathrm{R}$ Core Team, 2018). The overall diversity across the vertical strata was assessed via individual-based accumulation curves instead of sample-based curves as a result of the different sampling methods used to sample the communities of spiders living on the ground, trunk and canopy (i.e. the considered sampling effort unit was the individuals). Because the trunk diameter was not equal between the olive trees, the area of each sticky trap differed between samples; thus, the number of spiders captured with sticky traps was recorded as number of individuals per $\mathrm{m}^{2}$ of trap.

For ground spiders, a series of univariate and multivariate, parametric and nonparametric methods were used to investigate the spatial distribution of the different species and functional groups identified along the three sampling areas from the centre of the olive grove to the adjacent shrubland area.

First, the overall diversity across the horizontal strata was also assessed with individual-based accumulation curves. The total spider abundance $(n)$, the abundance of the dominant functional groups, the species richness $(S)$ and the Simpson index $(1-D)$ were calculated (Magurran, 2004). The effect of the sampling area (i.e. olive grove central, peripheral and shrubland areas) on each dependent variable was investigated using generalized estimating equations, comprising an extension of generalized linear models (Zuur et al., 2009; Pekár \& Brabec, 2018), followed by a post-hoc Tukey's test. For count data (i.e. abundance and richness), Poisson distribution was used. In all cases, the correlation structure used was 'exchangeable' (i.e. a single correlation parameter, $\rho$ ) and locality was used for clustering.

Because of the low number of groves $(n=5)$ and samples per area $(n=4)$, these results were corroborated by bootstrapping the overall mean of each response ( 999 bootstrap replicates) and its $95 \%$ confidence interval (CI) were generated.

Both for species and functional groups of spiders, a non-metric multidimensional scaling (NMDS) was carried out using the Bray-Curtis measure (999 permutations) that considers the presence or absence of taxa, as well as the abundance among samples, aiming to assess the variability in the community of ground spiders along the horizontal gradient. Two permutational multivariate analyses of variance (PERMANOVA), one for the species dataset and one for the functional groups dataset, were carried out using the Bray-Curtis measure ( 999 permutations) to corroborate the results of the NMDS analysis using the species and functional groups matrices as dependent variables and the sampled areas along the horizontal gradient as an explanatory variable. Also, the factor 'locality' was included in the model to account for the site effect.
Then, a similarity percentages (SIMPER) analysis was used (999 permutations) to uncover the species and functional groups that contributed to the within-groups dissimilarities. The average contribution of each species and functional group and the overall between-group Bray-Curtis measure was calculated for each pair of sampling areas (i.e. olive grove central area, olive grove margin area and shrubland area).

A set of indicator species for each sampling area was proposed by calculating the positive predictive power (A), sensitivity (B) and the statistical significance $(P<0.05)$ of the association between species and sampling areas in accordance with De Cáceres et al. (2010). We only considered those species with a positive predictive power (A) higher than 0.5 .

Finally, a co-inertia analysis ('cross-table' multivariate analysis) was performed to generate a gradient of species and functional groups along the horizontal gradient. The procedure consists of finding a co-structure between two sets of variables (the community matrix and the environmental matrix) that are linked by the same individuals, where the resulting sample scores are the most covariant (Dolédec \& Chessel, 1994). We performed the co-inertia analysis via principal component analysis separately for each matrix. Then, the scores of the principal component analysis were used to place each species or functional group along the $x$-axis and the environmental drivers along the $y$-axis. Finally, the correlation obtained for each 'taxa-driver' pair using the co-inertia analysis was plotted altogether.

\section{Results}

The whole community of spiders found in the study areas included nine functional groups: ambushers, foliage runner hunters, ground hunters, orb-web builders, sensing web-builders, sheet web builders, space web builders, stalkers and wandering sheet/tangle weavers; 28 families and 83 species (see Supporting information, Table S2).

Considering the vertical distribution, the ambusher species Philodromus lividus Simon, 1875 was the most abundant species in the canopy, followed by Philodromus albidus Kulczyński, 1911 and the orb-weaver Araniella cucurbitina (Clerck, 1757) (see Supporting information, Table S2). The most abundant group in this stratum belonged to the subfamily Erigoninae (Linyphiidae) (tiny wandering sheet/tangle weavers known as dwarf or money spiders), followed by Philodromidae (see Supporting information, Table S2). On the trunk, Erigoninae was also the most recorded group, followed by Philodromidae and Thomisidae (see Supporting information, Table S2).

On the ground of the olive grove, both central and peripheral areas were dominated by the ambusher Thanatus vulgaris Simon, 1870, followed by the ground hunter Alopecosa albofasciata (Brullé, 1832) and Zodarion styliferum (Simon, 1870) (see Supporting information, Table S2). Hogna Simon, 1885 was also abundant in the olive grove. The shrubland was dominated by the ground hunter Nomisia exornata (C. L. Koch, 1839), followed by A. albofasciata (see Supporting information, Table S2). Considering the horizontal distribution, the orb-web builders were absent from the shrubland, the sensing web builders were absent from the olive grove and the foliage runner hunters were not found in the olive grove central area (see Supporting information, Table S2). 
(A)

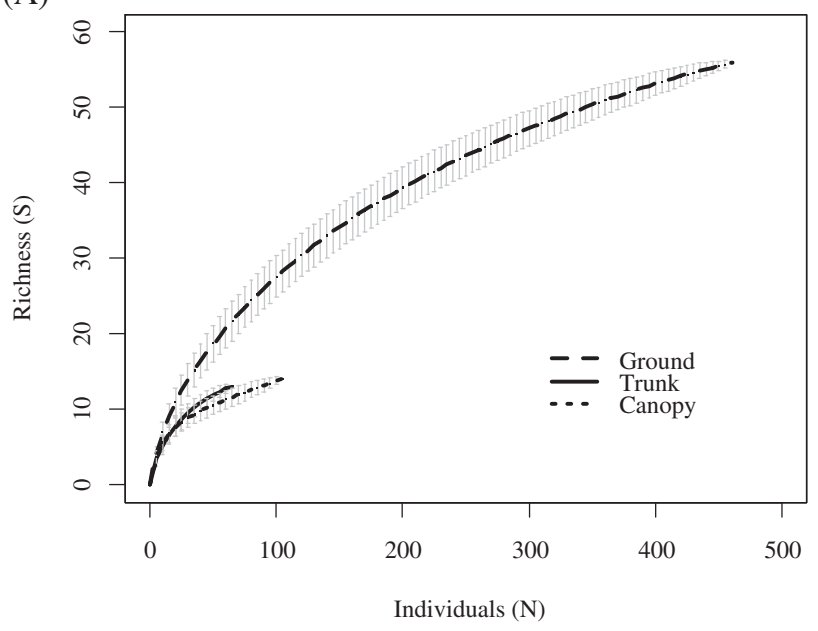

(B)

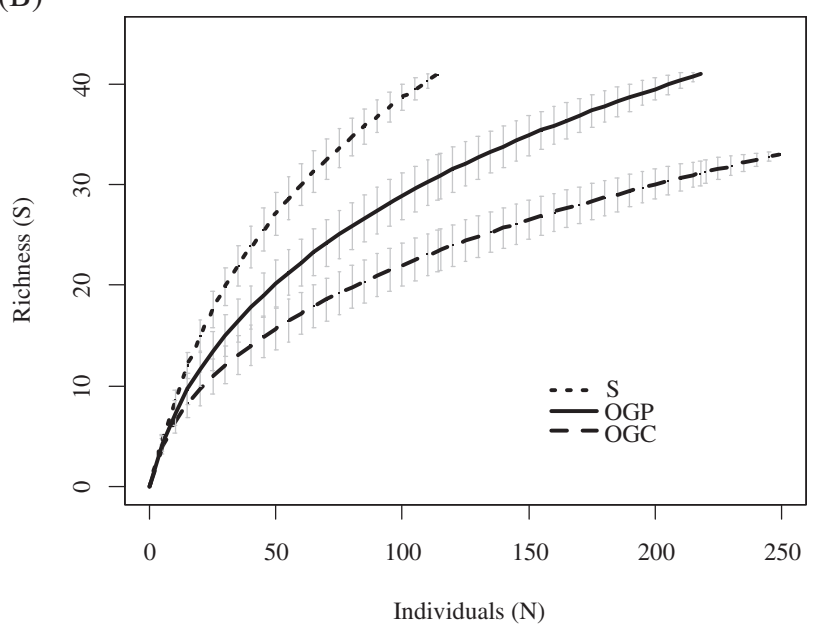

Figure 1 Richness of spider species found across a vertical gradient (i.e. ground, trunk and canopy) and a horizontal gradient (i.e. olive grove and an adjacent shrubland area) in Trás-Os-Montes (Portugal). (A) Species accumulation curves for the vertical. (B) Horizontal spatial gradient. OGC, olive grove central area; OGP, olive grove peripheral area; S, shrubland area. Vertical bars around lines represent the SE of the estimates.

Regarding the vertical distribution, the community of spiders sampled on the ground reached the highest number of species (Fig. 1A), whereas, horizontally, the species accumulation curves showed an increasing pattern in species richness from the olive grove central area to the shrubland area (Fig. 1B). However, the total spider abundance was statistically significantly lower only in the shrubland area (Fig. 2A). The species richness $(S)$ was not statistically significantly different across the horizontal distribution (Table 1) [mean (95\% CI): 5.00 (3.96-6.06), $5.00(4.14-5.86)$ and $4.45(3.39-5.47)$ species per sample in the olive grove central, peripheral and shrubland areas, respectively]. Also, the Simpson index $(1-D)$ did not significantly vary from the olive grove central area to the shrubland area (Table 1) [1.19 (0.977-1.409), $1.30(1.09-1.50)$ and $1.23(1.02-1.45)]$.

In terms of functional groups, the abundance of ambushers found in the shrubland area was statistically significantly lower than in the olive grove (Fig. $2 \mathrm{~B}$ and Table 1). The abundance of foliage runner hunters was significantly lower in the olive grove central area that in the peripheral and shrubland areas (Fig. 2C), whereas the abundance of ground hunters found in the olive grove peripheral area was significantly higher than in the shrubland area (Fig. 2D and Table 1). The abundance of stalkers significantly increased from the olive grove central area to the shrubland area (Fig. 2E). By contrast, the abundance of sheet web builders [0.25 (0.01-0.49), $0.45(0.01-0.88)$ and $0.70(0.00-1.40)]$ and wandering sheet/tangle weavers $[1.72$ (1.04-2.42), $1.20(0.63-1.77)$ and $0.95(0.40-1.51)]$ did not significantly differ among the three areas (Table 1).

The NMDS showed a significant change of the community of ground spiders across the horizontal gradient both in term of species (stress $=0.095$ ) and functional groups (stress $=0.151$ ) . In the case of species, there was a gradual and significant change from the olive grove central area to the shrubland area (Permanova: $F=2.2826$; d.f. $=2 ; P<0.01$ ) (Fig. $3 \mathrm{~A}$ ), and in terms of functional groups, the olive grove community was significantly separated from the shrubland community (PERMANOva: $F=3.6725$; d.f. $=2 ; P<0.01$ ) (Fig. 3B).
According to the SIMPER analysis, 10 species were responsible for $70 \%$ of the differences found between the communities of spiders sampled in the olive grove central and the peripheral area (see Supporting information, Table S2); 15 species were responsible for the differences found between the olive grove peripheral area and the adjacent shrubland; and 14 species were responsible for the differences found between the olive grove central area and the shrubland area (see Supporting information, Table S2). The highest differences were found between the olive grove central area and the shrubland area (see Supporting information, Table S3). In terms of functional groups, the ambushers and ground hunters were the most influential groups in all the cases, and the maximum overall dissimilarity was also observed between the olive grove central area and the shrubland area (see Supporting information, Table S4).

Thanatus vulgaris can be a potential bioindicator for the olive ground central area, Ozyptila pauxilla (Simon, 1870) for the olive ground peripheral area and Eratigena feminea (Simon, 1870) and Scytodes velutina Heineken \& Lowe, 1832 for the shrubland area (Table 2). These results were consistent with the co-inertia analysis for the species dataset $(\mathrm{RV}=0.172)$ that positioned $T$. vulgaris and $S$. velutina on the extreme of a gradient of species distribution across the horizontal spatial gradient (Fig. 4A). The co-inertia analysis for functional groups $(\mathrm{RV}=0.147)$ also supported the results of the NMDS by associating the foliage runner hunters, sheet web builders, sensing web builders and stalkers to the shrubland area, as well as the remaining functional groups to the olive grove (Fig. 4B).

\section{Discussion}

In the present study, the composition and structure of the community of spiders inhabiting the olive grove showed vertical and horizontal distributions that differed, respectively, from the ground to the olive tree canopy and from the olive grove to the adjacent shrubland. Considering the vertical distribution, 

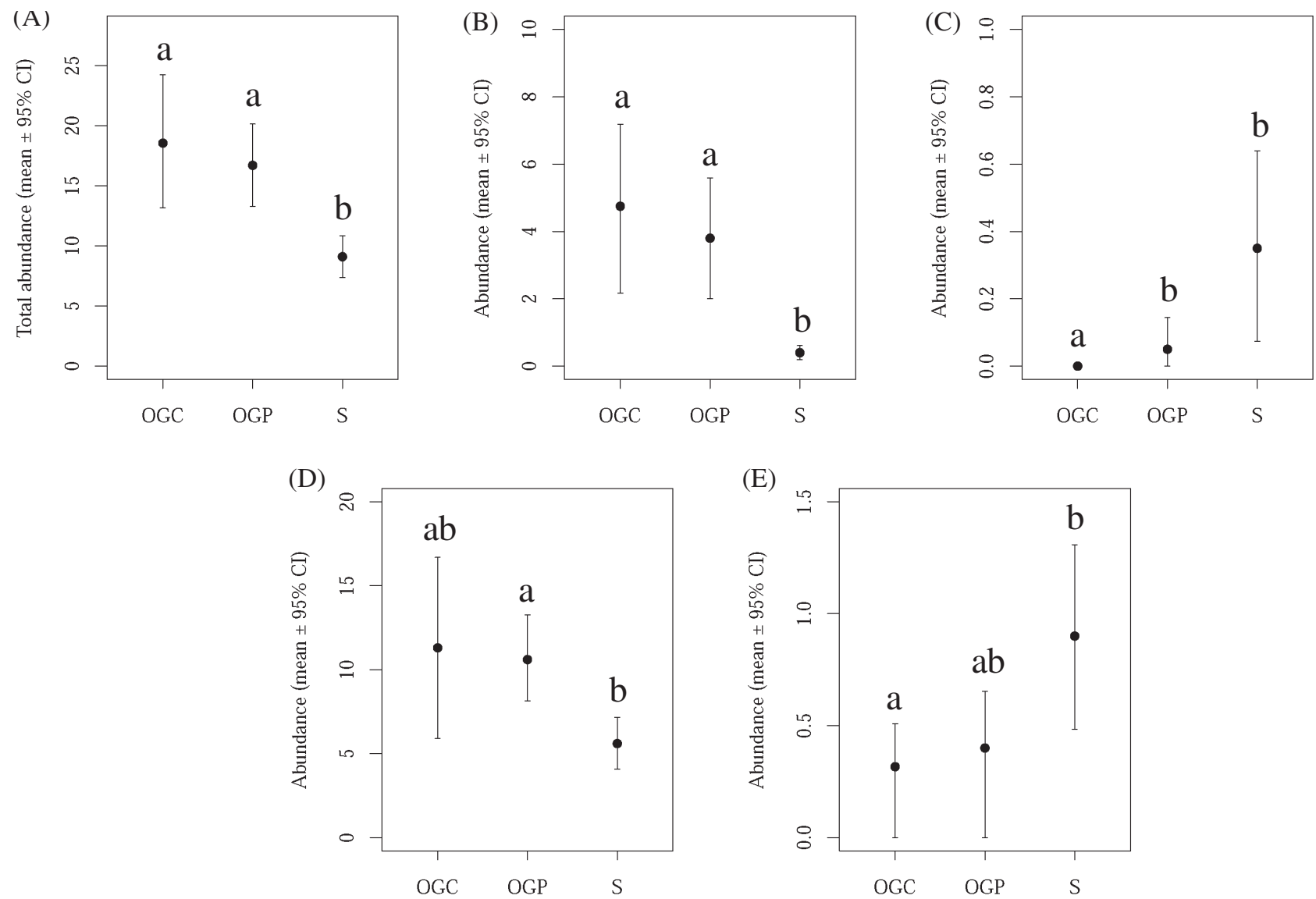

Figure 2 Composition and structure of the community of spiders across a horizontal spatial gradient (olive grove central area, olive grove peripheral area and the surrounding shrubland) in Trás-Os-Montes. Dots represent the mean and bars the 95\% confidence interval obtained by bootstrapping (999 replicates). Different lowercase letters above bars represent significant differences between sampling areas. OGC, olive grove central area; OGP, olive grove peripheral area; S, adjacent shrubland area. (A) Total spider abundance. (B) Abundance of ambushers. (C) Abundance of foliage runner hunters. (D) Abundance of ground hunters. (E) Abundance of stalkers.

Table 1 Summary of the marginal models outputs (generalized estimating equations) developed to test the effect of the sampling area on the community of spiders across the olive grove in Trás-Os-Montes (i.e. olive grove central area, olive grove peripheral area and an adjacent shrubland area

\begin{tabular}{llll}
\hline Dependent variable & $\chi^{2}$ & d.f. & $P$ \\
\hline Total spider abundance $(n)$ & 22.30 & 2 & $<0.01^{*}$ \\
Species richness $(S)$ & 3.92 & 2 & 0.14 \\
Simpson index $(1-D)$ & 0.22 & 2 & 0.89 \\
Abundance of ambushers & 23.00 & 2 & $<0.01^{*}$ \\
Abundance of foliage runner hunters & 5087 & 2 & $<0.01^{*}$ \\
Abundance of ground hunters & 7.17 & 2 & $0.03^{*}$ \\
Abundance of sheet web builders & 2.39 & 2 & 0.30 \\
Abundance of stalkers & 12.10 & 2 & $<0.01^{*}$ \\
Abundance of wandering sheet/tangle weavers & 1.94 & 2 & 0.38 \\
\hline
\end{tabular}

P. lividus and P. albidus were the most abundant species in the canopy of olive trees. The genus Philodromus Walckenaer, 1826 includes small and medium sized wandering ambusher spiders (i.e. the body length of P. lividus ranges from 4.19 to $5.04 \mathrm{~mm}$ in males and from 4.39 to $6.9 \mathrm{~mm}$ in females) (Nentwig et al., 2018) that are able to run fast on plant surfaces (Wolff \& Gorb, 2012). As a result of the occurrence of immature Philodromidae and the dominance of the adults among the community of spiders in the canopy and in the trunk, as well as the absence of Philodromus on the ground, it is suggested that some species of the genus may complete their life cycle in the canopy. Therefore, further attention should focus on specimens of Philodromus inhabiting the canopy because they could be useful natural enemies of olive tree pests. Indeed, different co-occurring species of Philodromus could encompass a complex of efficient natural enemies because of their complementary trophic niches in terms of prey size, similar niches in terms of to prey type and a preference for different microhabitats (Michalko \& Pekár, 2015a, 2015b).

Orb-weavers such as A. cucurbitina and other functional groups of web builders may also play an important role in the canopy as natural enemies. Picchi et al. (2017) found that the abundance of the olive fruit fly, $B$. oleae was negatively correlated with the abundance of sheet web spiders in the canopy.

In terms of total spider abundance in the olive tree canopy, Picchi et al. (2016) found a decreasing pattern from the centre towards the olive grove edge. In the present study, the high 

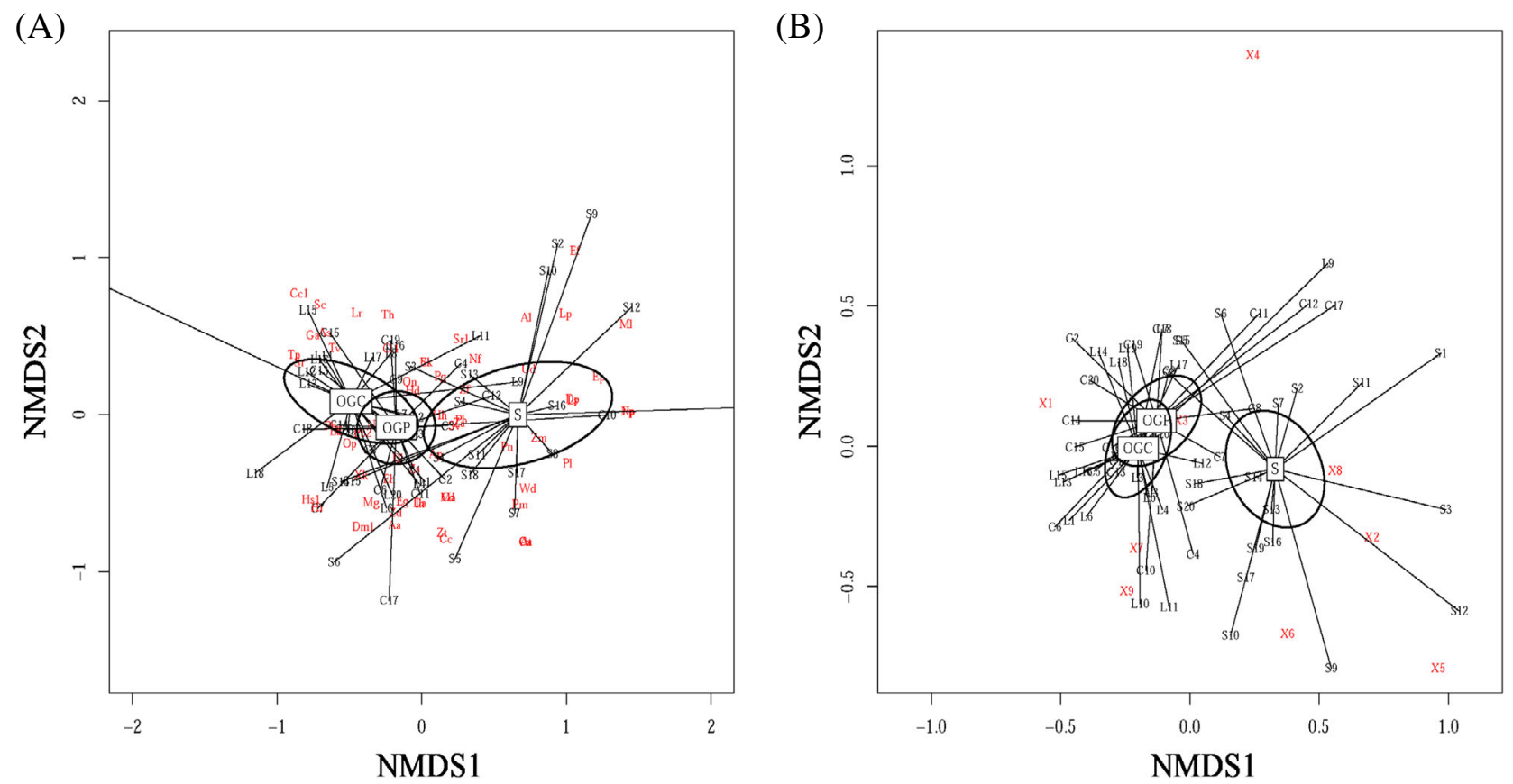

Figure 3 Non-metric multidimensional scaling (NMDS) analysis for (A) species and (B) functional groups of the community of ground spiders along the different strata of a horizontal gradient in the olive grove agroecosystem in Trás-Os-Montes (Portugal). OGC, olive grove central area; OGP, olive grove peripheral area; S, adjacent shrubland area. Samples are indicated by the 'C' (olive grove peripheral area), 'L' (olive grove central area) and 'S' (shrubland area), followed by a number. Species (in red) correspond to the codes indicated in the Supporting information (Table S2). Functional groups (in red) correspond to the codes indicated in the Supporting information (Table S2) preceded by ' $X$ '. Each sample (in black) is connected to its group centroid, and each centroid is surrounded by its $95 \%$ confidence limit. In (A), two samples (one on the left side and one on the right side) were left out of the plot area to facilitate the visualization.

Table 2 Ground spider species that can be bioindicators of agricultural practices along a horizontal spatial gradient in Trás-Os-Montes (Portugal) (i.e. olive grove central area, olive grove peripheral area and shrubland)

\begin{tabular}{|c|c|c|c|c|c|c|c|c|c|}
\hline \multirow[b]{2}{*}{ Candidate species } & \multirow[b]{2}{*}{ Functional group } & \multicolumn{3}{|c|}{ Positive predictive power } & \multicolumn{3}{|c|}{ Sensitivity } & \multirow[b]{2}{*}{ Indicator for } & \multirow[b]{2}{*}{$P$} \\
\hline & & OGC & OGP & $S$ & OGC & OGP & $S$ & & \\
\hline Thanatus vulgaris & Ambushers & 0.610 & 0.390 & 0.000 & 0.450 & 0.400 & 0.000 & Olive ground central area & 0.010 \\
\hline Ozyptila pauxilla & Ambushers & 0.387 & 0.563 & 0.050 & 0.450 & 0.300 & 0.100 & Olive ground peripheral area & 0.020 \\
\hline Eratigena feminea & Sheet web builders & 0.240 & 0.000 & 0.760 & 0.050 & 0.000 & 0.250 & Shrubland & 0.025 \\
\hline Scytodes velutina & Stalkers & 0.000 & 0.000 & 1.000 & 0.000 & 0.000 & 0.200 & Shrubland & 0.030 \\
\hline
\end{tabular}

OGC, olive grove central area; OGP, olive grove peripheral area; S, shrubland area. Positive predictive power values $>0.5$ are indicated in bold.

number of Erigoninae (Linyphiidae) both in the canopy and trunk suggests a high level of ballooning (i.e. aerial dispersion especially at immature stages). Our results agree with those obtained by Simonneau et al. (2016) who found the family Linyphiidae to be the most frequent 'ballooner' among the recorded spiders.

Benhadi-Marín et al. (2016) demonstrated that the lifespan of A. cucurbitina, the third most recorded species in the olive tree canopy, was negatively affected by the application of kaolin, a white aluminosilicate mineral clay that forms a particle film and is commonly sprayed as an alternative to pesticides. Thus, aerial dispersion could be seen as a strategy to escape from a seasonally disturbed habitat such as an agroecosystem (Simonneau et al., 2016), thus generating spurious diversity patterns.

On the ground, the community of spiders was dominated by T. vulgaris. All Thanatus C. L. Koch, 1837 species are of small and medium size (the body length of $T$. vulgaris ranges from 3.7 to $5.8 \mathrm{~mm}$ in males and from 6.1 to $9.1 \mathrm{~mm}$ in females) (Szita \& Samu, 2000; Nentwig et al., 2018). The genus includes epigeic diurnal hunting spiders that do not use a web for hunting or shelter; they are less agile than the plant dwellers of the genera Philodromus and Tibellus Simon, 1875 and they are found on open ground or on logs and stones (Dondale \& Redner, 1978; Szita \& Samu, 2000). Thanatus vulgaris is an holarctic species that has been described as synanthropic (i.e. a species that lives and benefit from artificial habitats created by humans) and has been found in dry steppes in Europe (Nentwig et al., 2018), which could justify its presence in a rain fed agroecosystem, such as was the case for the olive groves studied.

Alopecosa albofasciata was the second most abundant species in the central area of the olive grove. This agrees with the ecology of this stenochronous (i.e. short-lived species with rapid growth 

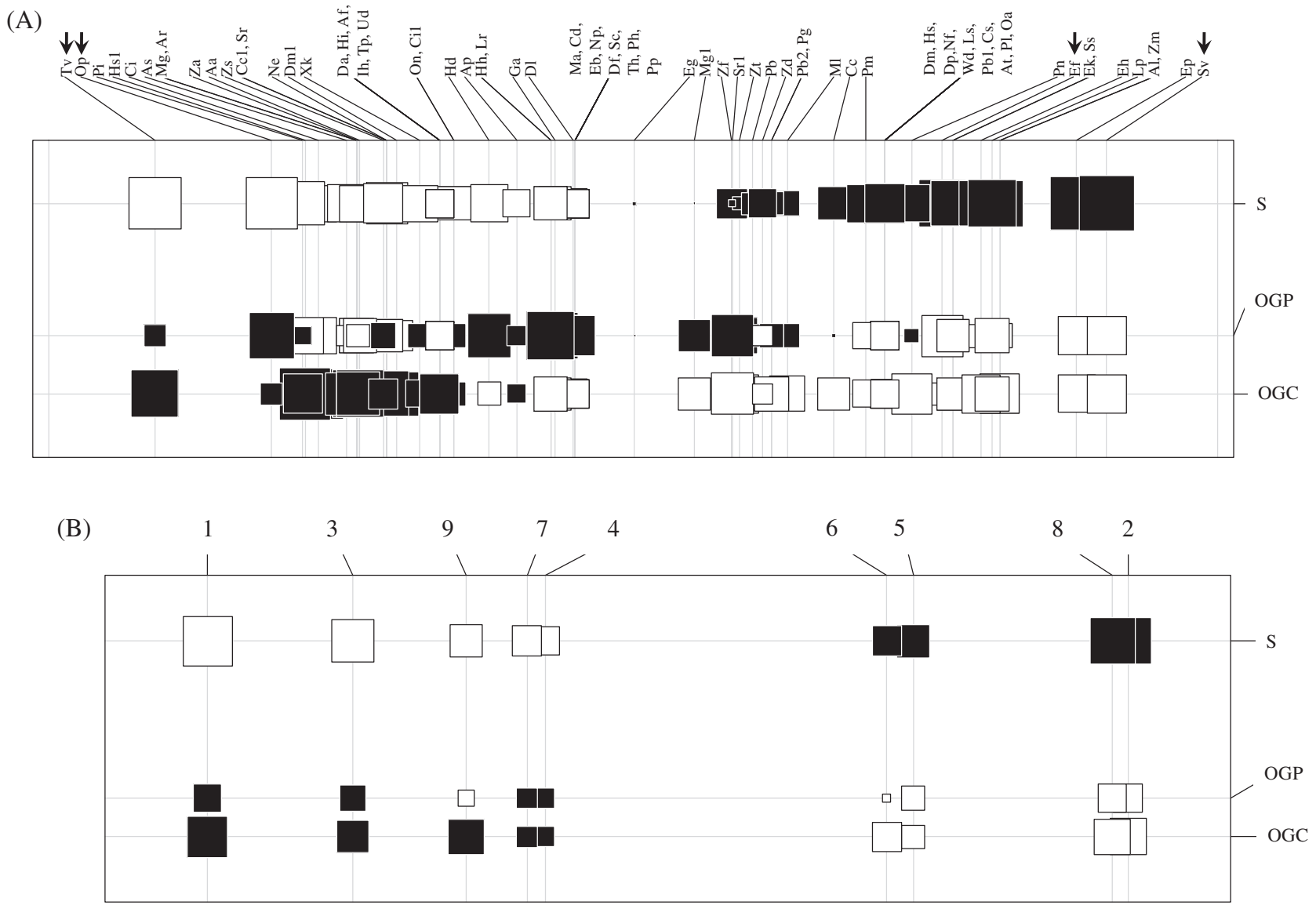

Figure 4 Coinertia analysis for the spatial distribution of species (A) and guilds (B) of ground spiders along a horizontal gradient from the olive grove to the adjacent semi-natural shrubland area in Trás-Os-Montes (Portugal). OGC, olive grove central area; OGP, olive grove peripheral area; S, adjacent shrubland area. Species and functional groups correspond to the codes indicated in the Supporting information (Table S2). In (A), arrows indicate the proposed indicators species. Black squares represent positive relationships and white squares negative relationships. Square sizes are proportional to the magnitude of correlation.

and maturation) circum-Mediterranean species, which lives in dry, open and sunny places (Lugetti \& Tongiorgi, 1969; Nentwig et al., 2018). Alopecosa Simon, 1885 species are also small and medium size spiders (body length of A. albofasciata ranges from 8 to $9 \mathrm{~mm}$ in males and from 10 to $12 \mathrm{~mm}$ in females) (Lugetti \& Tongiorgi, 1969; Nentwig et al., 2018). Alopecosa albofasciata has been reported from meadows, in the Mediterranean scrub, in the open areas of the forest, in the pine forests and in the olive groves (Lugetti \& Tongiorgi, 1969).

In the peripheral area, Z. styliferum was also the second most recorded species. The genus Zodarion Walckenaer, 1826 includes small myrmecophagic ground spiders (male and female body length ranging from 2.2 to $2.9 \mathrm{~mm}$ and 2.9 to $4.8 \mathrm{~mm}$, respectively, in Z. styliferum) (Pekár, 2004; Nentwig et al., 2018). Accordingly, the abundance of Zodarion species within the olive grove agroecosystem is strongly linked to the soil fauna that is numerically dominated by Formicidae (Santos et al., 2007).

We observed significant changes in the community of spiders from the central area of the olive grove towards the adjacent shrubland area. In terms of functional groups, the abundance of ambushers was significantly lower in the shrubland adjacent area. This is probably a result of dominance of $T$. vulgaris in the grove. Moreover, the species richness in the shrubland was not significantly different from those recorded in the olive grove. By contrast, the abundance of foliage runner hunters significantly increased toward the shrubland area. This increase was probably a result of the higher vegetation complexity within the shrubland area, which could provide a higher number of habitats than the vegetation cover of the olive grove ground thus reducing the intraguild competition (Finke \& Denno, 2002).

The agroecosystem margin usually present physical structures such as stone walls, trails, roads and different types of edges that may affect the local community composition. In the present study, Civizelotes dentatidens (Simon, 1914), Drassodes lapidosus (Walckenaer, 1802), Gnaphosa alacris Simon, 1878, Haplodrassus dalmatensis (L. Koch, 1866), Heser hispanus Senglet, 2012 and Setaphis carmeli (O. P.-Cambridge, 1872) represent a pool of species belonging to the family Gnaphosidae, which is composed mainly of nocturnal spiders commonly found sheltering under stones, being found exclusively in the peripheral area of the grove or linked to it. These species probably depend on 
physical structures such as logs and stones that can be used as refuges (Lecq et al., 2017).

Although we did not find significant differences between the total species richness in the shrubland and the olive grove, the accumulation curves indicate higher spider diversity in the shrubland area if the sampling effort would have increased to the same number of individuals captured in the grove. In terms of diversity patterns, Picchi et al. (2016) found that densities of Linyphiidae within the grove decreased with the proportion of shrubland in the surrounding landscape. We found that the foliage runner hunters, sensing web builders, sheet web builders and stalkers were linked to the adjacent shrubland area. Our results agree with those obtained by Langellotto and Denno (2004) who showed that different natural enemy guilds such as hunting spiders (foliage runner hunters and stalkers in the present study) and web-building spiders (sensing web builders and sheet web builders in the present study) strongly responded to higher habitat complexity.

The adjacent shrubland areas can also play an important role in biological control of pests, Picchi et al. (2017) reported an increasing predation pressure on exposed pupae of B. oleae in groves and suggested that the vegetation structure and physical characteristics of the Mediterranean shrubland such as dry and warm microclimates and rocky habitats might influence the ground dwelling community. Also, the adjacent shrubland area explained the differences found in the carabid community structure among olive groves at the landscape level (da Silva et al., 2017).

According to Samu and Szinetár (2002), agrobionts are indicators of arable habitats. Nevertheless, in terms of species, field studies are commonly context dependent; for example, our conclusions should be constrained to the region of Trás-os-Montes, although the extension of our interpretations to a wider geographical range can be approached from a functional point of view. In this sense, functional counterparts can be found between different regions. For example, Samu and Szinetár (2002) provided a list of agrobiont spiders in alfalfa and cereal crops, including the ambusher Tibellus oblongus (Walckenaer, 1802), which is a Philodromidae (ambusher) found among grass in wet and dry sunny places (Nentwig et al., 2018) that could be functionally analogous to T. vulgaris in our region and crop, and A. pulverulenta (Clerck, 1757), which is a Lycosidae (ground hunter) that could be functionally analogous to A. albofasciata in the present study. Considering the second indicator of the arable land in the present study, Ozyptila pauxilla (Simon, 1870) has also been found in the citrus agroecosystem (Mestre et al., 2012), which supports our proposal of it comprising an agrobiont species.

The olive grove and its surrounding semi-natural areas provide multiple habitats that support a diverse community of spiders in terms of functional groups and species. Some of these species are ecologically linked to each area being representative of them, which allows their use as bioindicators. Further research on agrobiont and indicator species among spiders within agroecosystems is mandatory with respect to uncovering the biotic and abiotic factors that could drive the changes on the community of spiders, as well as how these changes are related to management practices. Disentangling these management-habitat-community relationships is essential to enhance the effectiveness of potential natural enemies such as spiders via the implementation of low-impact agricultural management practices in arable landscapes.

\section{Acknowledgements}

This work was funded by Centro 2020 (Centro-01-0145-FEDER000007) through the project 'ReNATURE - Valorization of the Natural Endogenous Resources of the Centro Region'. The authors are indebted to all of the farmers who allowed access to their olive groves. Jacinto Benhadi-Marín is grateful to the Portuguese Foundation of Science and Technology (FCT) for financial support through the PhD grant SFRH/BD/97248/2013. This manuscript is part of Jacinto Benhadi-Marín's PhD thesis. The authors declare that they have no conflicts of interest.

\section{Supporting information}

Additional supporting information may be found online in the Supporting Information section at the end of the article.

Table S1 Main characteristics of the selected olive groves and their corresponding adjacent shrublands. OGT, olive grove topography; SAT, shrubland area topography; ATA, average tree age; OGA, olive grove altitude; SAL, shrubland altitude; OGA, Olive grove area; SAA, shrubland area; ADR, average distance between rows; ADIR, average distance between inter-rows.

Table S2 Total number of Araneae (N), richness (S) and spider guilds identified in all the samples collected at each strata (vertical and horizontal) in the five study areas in 2014. The code of each species corresponds to the codes used in the species-based non-metric multidimensional scaling (NMDS) analysis and co-inertia plot (Figs $3 \mathrm{~A}$ and 4A). The number (shown in parentheses) of each spider guild corresponds to the number used in the guild-based NMDS analysis and co-inertia plot (Figs 3B and 4B). The abundance of the spiders collected in the trunk is expressed as number of individuals $/ \mathrm{m}^{2}$ of sticky trap. OGC, olive grove central area; OGP, olive grove peripheral area; $\mathrm{S}$, shrubland area. *Richness of families.

Table S3 Results of the similarity percentages (SIMPER) analysis for the spider species collected along a horizontal gradient in the olive agroecosystem in Trás-os-Montes. Species presenting a superscript correspond to the pool of species that contributed at least to $70 \%$ of the differences between a pair of sampling areas: (1) OGC-OGP, (2) OGP-S and (3) OGC-S, respectively. OGC, olive grove central area; OGP, olive grove peripheral area; S, shrubland area. Average: average contribution to overall Bray-Curtis dissimilarity; sd: SD of contribution; P: permutation $P$-value (i.e. the probability of getting a larger or equal average contribution in random permutation of the group factor) $(P<0.01)$.

Table S4 Results of the similarity percentages (SIMPER) analysis for the functional groups of spiders collected along a horizontal gradient in the olive agroecosystem in Trás-os-Montes. Functional groups presenting a superscript correspond to the pool of functional groups that contributed at least to $70 \%$ of the differences between a pair of sampling areas: (1) OGC-OGP, (2) 
OGP-S and (3) OGC-S, respectively. OGC, olive grove central area; OGP, olive grove peripheral area; $\mathrm{S}$, shrubland area. Average: average contribution to overall Bray-Curtis dissimilarity; sd: SD of contribution; P: permutation $P$-value (i.e. the probability of getting a larger or equal average contribution in random permutation of the group factor) $(P<0.01)$.

\section{References}

Benhadi-Marín, J., Pereira, J.A. \& Santos, S.A.P. (2016) Effects of kaolin particle films on the life span of an orb-weaver spider. Chemosphere, 144, 918-924.

Benhadi-Marín, J., Pereira, J.A., Barrientos, J.A., Sousa, J.P. \& Santos, S.A.P. (2018) Stones on the ground in olive groves promote the presence of spiders (Araneae). European Journal of Entomology, 115, $372-379$.

Blitzer, E.J., Dormann, C.F., Holzschuh, A., Klein, A.M., Rand, T.A. \& Tscharntke, T. (2012) Spillover of functionally important organisms between managed and natural habitats. Agriculture Ecosystems \& Environment, 146, 34-43.

Cárdenas, M. 2008. Análisis de la actividad ecológica de las arañas en el agroecosistema del olivar. PhD Thesis, Universidad de Granada: Granada, Spain.

Cárdenas, M. \& Barrientos, J.A. (2011) Spiders from Andalusian olive groves (Arachnida; Araneae). Faunistic aspects. Zoologica Baetica, 22, 99-136.

Cárdenas, M., Pascual, F., Campos, M. \& Pékar, S. (2015) The spider assemblage of olive groves under three management systems. Environmental Entomology, 44, 509-518.

Cardoso, P., Pekár, S., Jocqué, R. \& Coddington, J.A. (2011) Global patterns of guild composition and functional diversity of spiders. PLoS ONE, 6, e21710.

Civantos, M. (1999) Olive Pest and Disease Management. Conseil Oleicole International, Spain.

Dainese, M., Schneider, G., Krauss, J. \& Steffan-Dewenter, I. (2017) Complementarity among natural enemies enhances pest suppression. Scientific Reports, 7, 8172.

da Silva, P.M., Oliveira, J., Ferreira, A. et al. (2017) Habitat structure and neighbor linear features influence more carabids functional diversity in olive groves than the farming system. Ecological Indicators, 79, $128-138$.

De Cáceres, M., Legendre, P. \& Moretti, M. (2010) Improving indicator species analysis by combining groups of sites. Oikos, 119, 1674-1684.

Dolédec, S. \& Chessel, D. (1994) Co-inertia analysis: an alternative method for studying species environment relationships. Freshwater Biology, 31, 277-294.

Dondale, C.D. \& Redner, J.H. (1978) The Insects and Arachnids of Canada, Part 5. The Crab Spiders of Canada and Alaska, Araneae: Philodromidae and Thomisidae, Vol. 1663, pp. 1-255. Research Branch Agriculture Canada Publication, Canada.

FAOSTAT, 2018. FAOSTAT Statistics Database. Food and Agriculture Organization of the United Nations. Available at http://www.fao.org/ faostat/en/ [accessed on 18 August 2018.

Fick, S.E. \& Hijmans, R.J. (2017) Worldclim 2: New 1-km spatial resolution climate surfaces for global land areas. International Journal of Climatology. Available at http://worldclim.org/version2 [accessed on 18 February 2018], 37, 4302, 4315.

Finke, D.L. \& Denno, R.F. (2002) Intraguild predation diminished in complex-structured vegetation: implications for prey suppression. Ecology, 83, 643-652.

Ghavami, S. (2008) The potential of predatory spiders as biological control agents of cotton pests in Tehran provinces of Iran. Asian Journal of Experimental Sciences, 22, 303-306.
Hooks, C.R.R., Pandey, R.R. \& Johnson, M.W. (2003) Impact of avian and arthropod predation on lepidopteran caterpillar densities and plant productivity in an ephemeral agroecosystem. Ecological Entomology, 28, 522-532.

Isaia, M., Beikes, S., Paschetta, M., Sarvajayakesavalu, S. \& Badino, G. 2008. Spiders as potential biological controller in apple orchards infested by Cydia spp. (Lepidoptera: Tortricidae), Proceedings of the 24th European Congress of Arachnology, Bern, Switzerland, pp. 79-88. Natural History Museum of Bern, Bern, Switzerland.

Landis, D.A., Wratten, S.D. \& Gurr, G.M. (2000) Habitat management to conserve natural enemies of arthropod pests in agriculture. Annиal Review of Entomology, 45, 175-201.

Langellotto, G.A. \& Denno, R.F. (2004) Responses of invertebrate natural enemies to complex-structured habitats: a meta-analytical synthesis. Oecologia, 139, 1-10.

Lecq, S., Loisel, A., Brischoux, F., Mullin, S.J. \& Bonnet, X. (2017) Importance of ground refuges for the biodiversity in agricultural hedgerows. Ecological Indicators, 72, 615-626.

Lugetti, G. \& Tongiorgi, P. (1969) Ricerche sul genere Alopecosa Simon (Araneae-Lycosidae). Atti della Società Toscana di Scienze Naturali (B), 76, 1-100.

Magurran, A.E. (2004) Measuring Biological Diversity. Blackwell, Malden, MA.

Marc, P., Canard, A. \& Ysnel, F. (1999) Spiders (Araneae) useful for pest limitation and bioindication. Agriculture Ecosystems \& Environment, 74, 229-273.

Mestre, L., Piñol, J., Barrientos, J.A., Cama, A. \& Espadaler, X. (2012) Effects of ant competition and bird predation on the spider assemblage of a citrus grove. Basic and Applied Ecology, 13, 355-362.

Michalko, R. \& Pekár, S. (2015a) Niche partitioning and niche filtering jointly mediate the coexistence of three closely related spider species (Araneae, Philodromidae). Ecological Entomology, 40, 22-33.

Michalko, R. \& Pekár, S. (2015b) The biocontrol potential of Philodromus (Araneae, Philodromidae) spiders for the suppression of pome fruit orchard pests. Biological Control, 82, 13-20.

Michalko, R., Pekár, S. \& Entling, M.H. (2019) An updated perspective on spiders as generalist predators in biological control. Oecologia, 189, $21-36$

Morris, T., Symondson, W.O.C., Kidd, N.A.C. \& Campos, M. (1999) Las arañas y su incidencia sobre Prays oleae en el olivar. Boletín de Sanidad Vegetal. Plagas, 25, 475-489.

Nentwig, W., Blick, T., Gloor, D., Hänggi, A. \& Kropf, C. 2018. Spiders of Europe. Available at: www.araneae.unibe.ch. Version 01.2018 [accessed on 2 February 2018].

Nicholls, C.I., Parrella, M. \& Altieri, M.A. (2001) The effects of a vegetational corridor on the abundance and dispersal of insect biodiversity within a northern California organic vineyard. Landscape Ecology, 16, 133-146.

Oelbermann, K. \& Scheu, S. (2009) Control of aphids on wheat by generalist predators: effects of predator density and the presence of alternative prey. Entomologia Experimentalis et Applicata, 132 225-231.

Peel, M.C., Grieser, J., Beck, C., Rudolf, B. \& Rubel, F. (2007) Updated world map of the Koppen-Geiger climate classification. Meteorologische Zeitschrift, 15, 259-263.

Pekár, S. (2004) Predatory behavior of two European ant-eating spiders (Araneae, Zodariidae). The Journal of Arachnology, 32, 31-41.

Pekár, S. \& Brabec, M. (2018) Generalized estimating equations: a pragmatic and flexible approach to the marginal GLM modelling of correlated data in the behavioural sciences. Ethology, 124, $86-93$.

Pekár, S., Michalko, R., Líznarová, E., Loverre, P. \& Černecká, L. (2015) Biological control in winter: novel evidence for the importance of generalist predators. Journal of Applied Ecology, 52, 270-279. 
Picchi, M.S., Bocci, G., Petacchi, R. \& Entling, M.H. (2016) Effects of local and landscape factors on spiders and olive fruit flies. Agriculture, Ecosystems and Environment, 222, 138-147.

Picchi, M.S., Marchi, S., Albertini, A. \& Petacchi, R. (2017) Organic management of olive orchards increases the predation rate of overwintering pupae of Bactrocera oleae (Diptera: Tephritidae). Biological Control, 108, 9-15.

R Core Team (2018) R: A Language and Environment for Statistical Computing. R Foundation for Statistical Computing, Vienna, Austria. Available at: http://www.R-project.org [accessed on 2 January 2018].

Samu, F. \& Szinetár, C. (2002) On the nature of agrobiont spiders. Journal of Arachnology, 30, 389-402.

Santos, S.A.P., Cabanas, J.E. \& Pereira, J.A. (2007) Abundance and diversity of soil arthropods in olive grove ecosystem (Portugal): effect of pitfall trap type. European Journal of Soil Biology, 43, 77-83.

Simonneau, M., Courtial, C. \& Pétillon, J. (2016) Phenological and meteorological determinants of spider ballooning in an agricultural landscape. Comptes Rendus Biologies, 339, 408-416.
Szita, É. \& Samu, F. (2000) Taxonomical review of Thanatus species (Philodromidae, Araneae) of Hungary. Acta Zoologica Academiae Scientiarum Hungaricae, 46, 155-179.

Uetz, G.W., Halaj, J. \& Cady, A. (1999) Guild structure of spiders in mayor crops. The Journal of Arachnology, 27, 270-280.

Wyss, E., Niggli, U. \& Nentwig, W. (1995) The impact of spider on aphid populations in a strip-managed apple orchard. Journal of Applied Entomology, 119, 473-478.

Wolff, J.O. \& Gorb, S.N. (2012) Surface roughness effects on attachment ability of the spider Philodromus dispar (Araneae, Philodromidae). The Journal of Experimental Biology, 215, 179-184.

Zuur, A., Ieno, E.N., Walker, N., Saveliev, A.A. \& Smith, G.M. (2009) Mixed Effects Models and Extensions in Ecology with R. Springer, New York, New York.

Accepted 25 July 2019 